Pure \& Appl. Chem., Vo1. 49, pp. 857 - 870. Pergamon Press, 1977. Printed in Great Britain.

CRYPTATES: MACROPOLYCYCLIC INCLUSION COMPLEXES

J.M. Lehn

Institut Le Bel, Université Louis Pasteur, 4 Rue Blaise Pascal

67070 Strasbourg Cédex, France.

Abstract - Macropolycyclic ligands containing appropriate binding sites and cavities of suitable size and shape, may be designed so as to display molecular recognition in the formation of selective inclusion complexes, cryptates, with metal cations, but also with anions and molecules. Macrobicyclic ligands B form highly stable and selective alkali and alkaline-earth cryptates, displaying a pronounced cryptate effect on both stability and selectivity with respect to macromonocyclic ligands. Toxic heavy metal cations and transition netal cations may be selectively complexed by replacing oxygen by nitrogen binding sites. Alkali cryptates may also be considered as a class of very large counterions which enable the isolation of unusual species like alkali metal anions or cluster anions. Cylindrical macrotricyclic ligands $C$ contain two metal cation sites and form both mononuclear and binuclear metal cation cryptates. Their structure, the relative position of the cations and the complexation properties may be monitored via ligand design. Spheroidal macrotricyclic ligands $D$ effect tetrahedral recognition of small molecules or ions; they may be considered as topologically. optimal receptors for the ammonium ion, the water molecule, the halide ions, with which they form cryptates where the substrate is held in the intramolecular cavity by a tetrahedral array of hydrogen bonds.

Prospects for the design of other macropolycyclic receptors, of polynuclear complexes and of "cascade" complexes are analyzed.

\title{
INTRODUCTION
}

Macropolycyclic ligands form a broad family of substances overlapping both organic and inorganic chemistry. As organic molecules they are part of a class of molecules of intermediate size, mesomolecules, which may present a multitude of properties by the mere token of their size and the resulting palette of structural variations, while also being challenging synthetic targets. As complexing agents, they permeate the area of molecular recognition (Ref.1) since their structural features (topology, binding sites, layer effects) (Ref.1) determine the stability, selectivity and properties of their complexes with inorganic ions. Finally, from the point of view of inorganic chemistry, they represent a class of ligands, containing molecular cavities, which may be rationally designed to form inclusion 
complexes, cryptates, (Ref.1) displaying a wide range of properties.

Among the various facets of the inorganic chemistry of macropolycyclic ligands one may cite: 1) new topologies of the coordination shell; 2) high complexation stabilities resulting from a generalyzed chelate effect, the cryptate effect; 3) high selectivities by recognition of inorganic cations via a rigid ligand coordination shell (tetrahedral, trigonal bipyramidal, octahedral, spherical recognition); 4) stable and selective unusual complexes with inorganic species like alkali cations, the halide ions or inorganic molecules; 5) polynuclear complexes of specified topologies, imposing intercation distances and relative orientations; 6) stabilization of unusual species, like metal anions, clusters, uncommon oxidation states; 7) bioinorganic models; 8) cascade complexes in which a substrate may be included between metal cations which are themselves held by the ligand; 9) catalysis for instance in cascade complexes and/or by cation activation via a coordination shell designed for preferential complexation of the transition state. It thus appear that the chemistry of macropolycyclic ligands and of their cryptates may have a broad impact in both fundamental as well as applied research at the ternary meeting point of three major fields of chemistry: organic, inorganic, and biochemistry.

We shall summarize here results related mainly to the inorganic aspects of the chemistry of macropolycyclic cryptates, leaving aside the organic chemistry involved although it may constitute the largest fraction of the work. More detailed discussions are found in the original literature. Much work has been done in recent years on macrocyclic complexes of alkali and alkaline-earth cations (Ref.2 \& 3) and of transition metal cations (Ref.4 and references therein). Topologically, macrocycles A define two dimensional, circular cavities. Ligands of higher cyclic order contain three-dimensional, spheroldal, cavities. Such is the case for the macrobicyclic, B, and macrotricyclic cryptands. The latter may be either of cylindrical, $C$, or spheroidal, D, topology. The bis-macrocycles $E$ obtained in the course of the synthesis of $\mathrm{C}$ type ligands, may also present interesting properties.

ine present discussion will cover our work on cation, anion and molecule cryptate formed by ligands of type B, C and D containing appropriate binding sites and cavities.

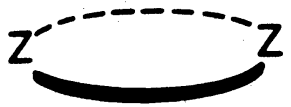

A

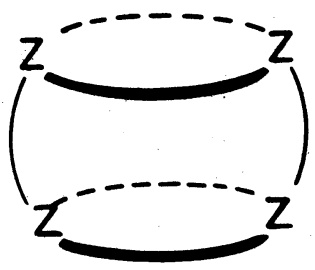

C

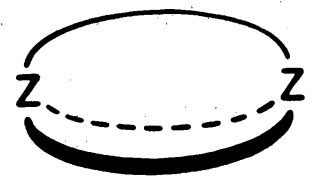

B

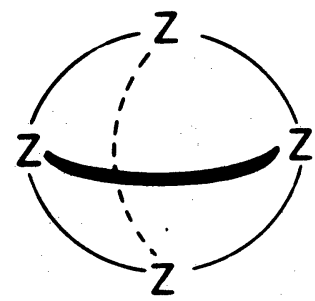

D

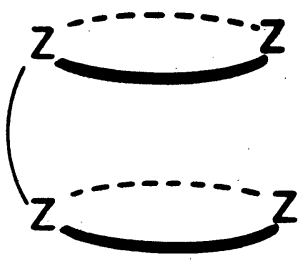

$\mathbf{E}$ 


\section{MACROBICYCLIC CRYPTATES}

Macrobicyclic ligands in their in-in conformation contain an internal cavity of about spherical shape. They should be especially well suited for the recognition of spherical cations, the alkali and alkaline-earth cations (AC's and AEC's). Appreciably stable complexes of AC's and AEC's are known for only about ten years; natural and synthetic macrocyclic ligands have been discovered (Ref.2 \& 3), and macrobicyclic ligands form even more stable complexes in consonance with their topology.

A series of macrobicyclic molecules $\underline{\underline{1}}-\underline{\underline{7}}$ has been first synthesized (Ref.5), whose multiple oxygen binding sites are best suited for AC and AEC complexation.

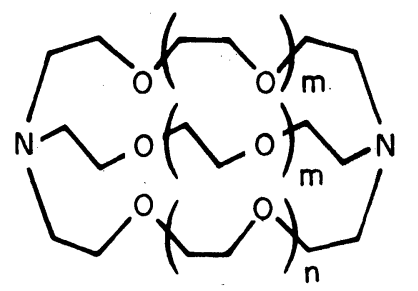

$$
\begin{array}{ll}
\underline{\underline{1}}[1.1 .1] & m=n=0 \\
\underline{\underline{2}}[2.1 .1] & m=0, n=1 \\
\underline{\underline{3}}[2.2 .1] & m=1, n=0 \\
\underline{\underline{4}}[2.2 .2] & m=n=1
\end{array}
$$$$
\underline{\underline{5}}[3.2 .2] \quad m=1, n=2
$$$$
\underline{\underline{6}}[3.3 .2] \quad m=2, n=1
$$$$
\underline{\underline{7}}[3.3 .3] \quad \mathrm{m}=\mathrm{n}=2
$$

Indeed, these substances form complexes with salts of a number of metal cations especially $A C$ and AEC's as may be observed by characteristic changes in the NMR spectrum of the ligand and by dissolution of solid inorganic salts in organic solvents in which they are otherwise insoluble. These complexes are inclusion complexes (Ref.6), cryptates, in which the cation is contained in the center of the molecular cavity of the macrobicycle in the in-in form (see Fig. 1). The structure has been confirmed by $x$-Ray crystallographic determinations on a number of complexes with various cations (Ref.7 and references in Ref.1).

The first two steps have thus been realized: synthesis of the ligands and detection of complex formation with AC's, AEC's and various other cations. The next questions are then: how stable are these cryptates? Is there any gain over the macrocyclic ones? How can one monitor stability and selectivity via modifications of ligand structure?

\section{Stability and selectivity of [2]-cryptates (Ref. 8)}

Cryptate formation corresponds to the equilibrium represented in Fig. 1 for ligand $\underline{=}$, [2.2.2]. Measurement of the corresponding stability constants shows that cryptands $\underline{\underline{2}}, \underline{\underline{3}}, \underline{\underline{4}}$ form complexes with suitable AC's and AEC's, which are several orders of magnitude higher than those of natural (Ref.9) or synthetic macrocyclic ligands (e.g. valinomycin). They thus function as receptors for spherical cations.
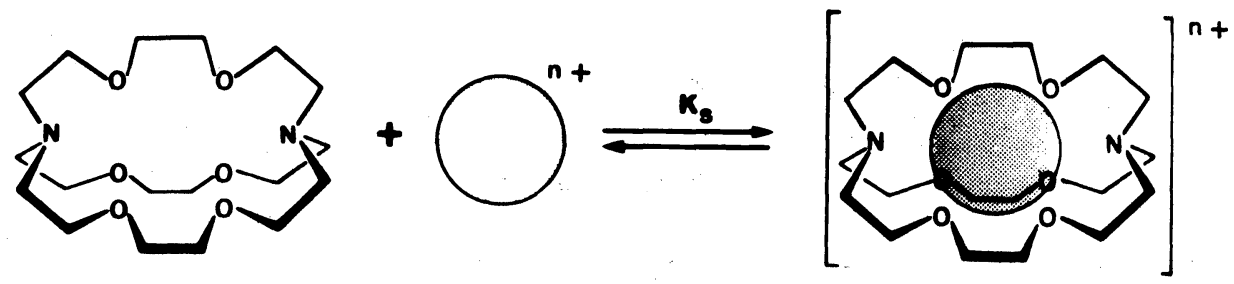

Fig. 1. Equilibrium for the formation of a cryptate inclusion complex between the macrobicyclic ligand [2.2.2], taken as an example, and a metal cation. 
An increase in stability constant (in methanol) of about $10^{4}$, the macrocyclic effect, is found between the $\mathrm{K}^{+}$complexes of the acyclic polyether $\mathrm{CH}_{3}-\left(\mathrm{OCH}_{2} \mathrm{CH}_{2}\right)_{5}-\mathrm{OHCH}_{3}$ and its cyclic analog 18-crown-6, $\underset{=}{=}$ (Ref.2). An even larger macrobicyclic cryptate effect on stabilities is found: indeed the stability of the $\left[\mathrm{K}^{+} \subset 2.2 .2\right]$ cryptate is higher by a factor of about $10^{5}$, than the stability of the $\mathrm{K}^{+}$complex of the monocyclic ligand $\underline{\underline{9}}$ which results exactly from the opening of one bridge of the [2.2.2] cryptand.

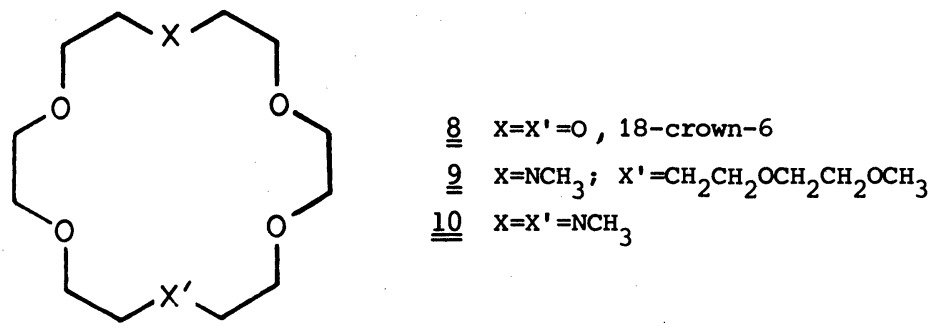

Thus, the bicyclic topology of the ligand [2.2.2] is of foremost importance in strongly increasing the stability of the complex. The same holds for AEC's, where again [Ba $\left.{ }^{2+} \mathrm{C} 2.2 .2\right]$ is $10^{5}$ times more stable than the $\mathrm{Ba}^{2+}$ complex of the macrocycle 10 and even more stable than the $\mathrm{Ba}^{2+}$ complex of polyanionic chelating ligands like EDTA. [2.2.2] is able to solubilize $\mathrm{BaSO}_{4}$ in water up to about $50 \mathrm{~g} / \mathrm{liter}$, an increase in solubility by a factor of more than $10^{4}$ !
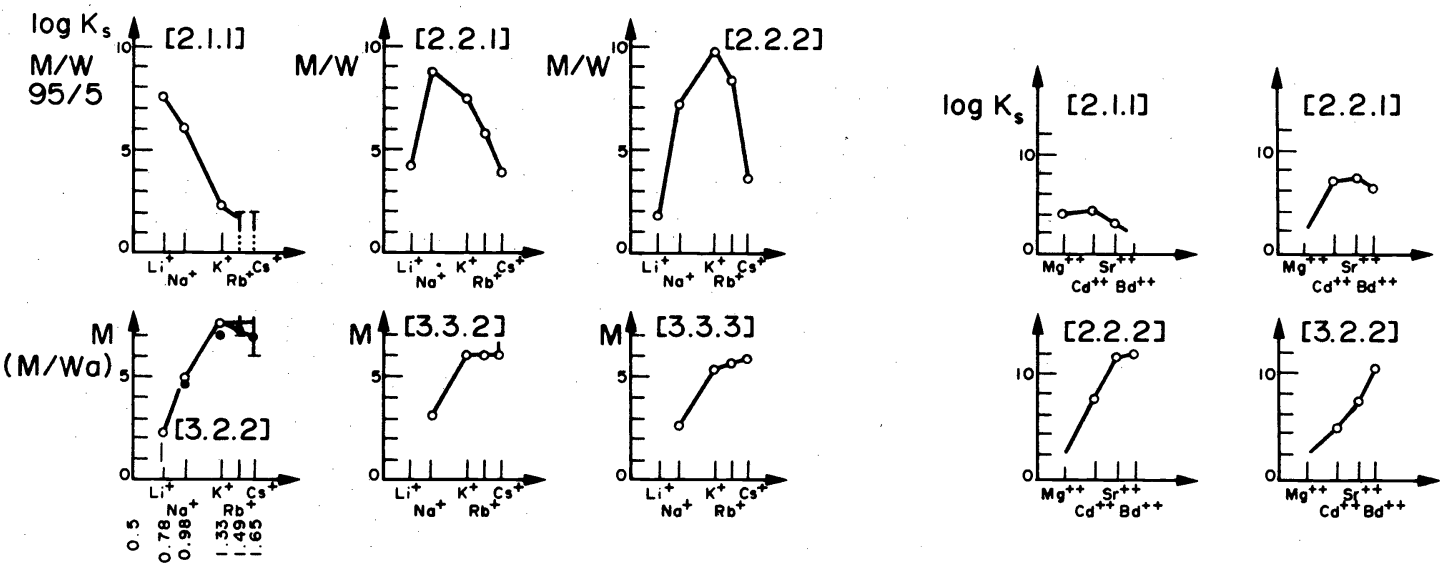

Fig. 2. Stability constants of the alkali cryptates (left; in methanol/water $\mathrm{M} / \mathrm{W} 95 / 5$ or in pure methanol $\mathrm{M}$ at $25^{\circ}$ ) and of the alkaline-earth cryptates (right; in water at $25^{\circ}$ ) formed by ligands $\underline{\underline{2}}-\underline{\underline{Z}}$.

The selectivity of the [2]-cryptates of AC's and AEC's presents remarkable features. Pronounced and unusual selectivities are found. Lengthening the bridges of the macrobicyclic system from [1.1.1] to [3.3.3] leads to a large but gradual change in size of the intramolecular cavity from about 1.2 to $4.8 \AA$ (Ref.1). As a result the stabilities of the complexes are indeed greatly affected from one ligand to the other. They agree with a simple criterion of cavity selectivity, the preferred cation being that whose size most closely fits the cavity. The cryptands $[2.1 .1],[2.2 .1]$ and $[2.2 .2]$ thus complex preferentially $\mathrm{Li}^{+}, \mathrm{Na}^{+}$ 
and $\mathrm{k}^{+}$respectively. They present peak selectivity, being able to discrimate against cations which are either smaller or larger than their cavity. Again the bicyclic topology is expected to play a major role since contraction or expansion of the cavity should be more difficult than in macrocyclic ligands. Plateau selectivity is observed for the large, more flexible ligands $\stackrel{5}{=} \underline{-}$ which have high $\mathrm{K}^{+} / \mathrm{Na}^{+}$selectivity but show little selectivity among $\mathrm{K}^{+}, \mathrm{Rb}^{+}, \mathrm{Cs}^{+}$. The same behaviour is presented by the macrocyclic antibiotics like valinomycin (Ref.9). Some striking selectivities are also observed among AEC's. Whereas the anionic chelate ligands display usually a high preference for $\mathrm{Ca}^{2+}$ over $\mathrm{Sr}^{2+}$ and $\mathrm{Ba}^{2+}$, [2.2.2] shows the unique, very high, $\mathrm{Sr}^{2+}, \mathrm{Ba}^{2+}>\mathrm{Ca}^{2+}$ stability sequence, a property of interest for the decorporation of radioactive strontium from contamined organisms (Ref.10). Control over $\mathrm{M}^{2+} / \mathrm{M}^{+}$selectivity may be achieved by increasing ligand thickness or removing binding sites (Ref.11). The latter effect is clearly shown by comparing cryptands [2.2.2] and $\left[2.2 . \mathrm{C}_{8}\right], \underline{11}$. Whereas the first has a complexation selectivity $\mathrm{Ba}^{2+} / \mathrm{K}^{+} \sim 10^{4}$, the latter gives $<10^{-2}$ for the same ratio. The loss of two oxygen binding sites in $\left[2.2 . c_{8}\right]$ as compared to [2.2.2] and the difficult access of solvent molecules to the efficiently shielded cation destabilize the doubly charged $\mathrm{Ba}^{2+}$ complex much more than the $\mathrm{K}^{+}$complex, thus reversing the selectivity by a factor $>10^{6}$. Similar transformations can be performed for other $\mathrm{M}^{2+} / \mathrm{M}^{+}$couples.

The special complexation properties of the macrobicyclic ligands, define a cryptate effect characterized by a high stability, a high selectivity of complexation and efficient shielding of the complexed cation from the environment. This latter feature is illustrated by the solvent independence of lithium-7 NMR signal of $\left[\mathrm{Li}^{+} \subset 2.1 .1\right]$ (Ref.12).

Internal protonation of the ligands leads to proton cryptates which display extremely slow exchange rates in the cases of [2.1.1] and, even much more so, [1.1.1] whose internally diprotonated form is only very slowly deprotonated in $5 \mathrm{~N} \mathrm{KOH}$ at $60^{\circ}$ ! (Ref.5b). Calorimetric studies of cryptate formation show that the alkali cryptates usually have large enthalpies and negative entropies of formation and that the cryptate effect is of enthalpic origin (Ref.13).

\section{Effect of Binding Sites.}

The replacement of oxygen binding sites in cryptands $\stackrel{2-4}{=}$ by nitrogen or sulfur leads to a decrease in electrostatic interactions. Indeed the sulfur or nitrogen containing cryptands 12-16 display a rapid decrease of stability and selectivity of the AC and AEC complexes as the number of oxygen sites decreases (Ref.14 \& 15). However new and interesting complexation selectivities are found with other cations.

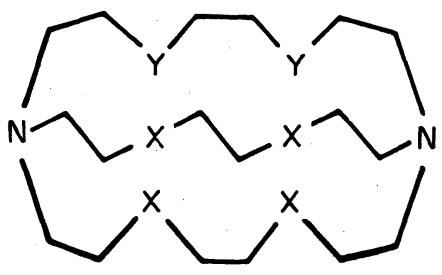

\begin{tabular}{|c|c|c|}
\hline $\mathrm{X}=\mathrm{O}, \mathrm{Y}=\mathrm{CH}_{2}$ & $\underline{\underline{15}}$ & $\mathrm{X}=\mathrm{O}, \quad \mathrm{Y}=\mathrm{NCH}_{3}$ \\
\hline$X=0, \quad Y=S$ & $\underline{\underline{16}}$ & $\mathrm{X}=\mathrm{NCH}_{3}, \quad \mathrm{Y}=0$ \\
\hline$X=S, \quad Y=0$ & $\underline{\underline{17}}$ & $\mathrm{X}=\mathrm{O}, \quad \mathrm{Y}=\mathrm{NCH}_{2} \mathrm{CH}_{2} \mathrm{COOH}$ \\
\hline
\end{tabular}


The complexation selectivity is strongly shifted in favour of cations like $\mathrm{Ag}^{+}, \mathrm{Tl}^{+}, \mathrm{Cd}^{2+}$, $\mathrm{Pb}^{2+}$. Indeed the $\mathrm{Tl}^{+} / \mathrm{K}^{+}$selectivity is 8 for [2.2.2] and 600 for 15 . Similarly the stability of the $\mathrm{Cd}^{2+}$ and $\mathrm{Pb}^{2+}$ complexes of 15 is higher than with [2.2.2] by about $10^{5}$ and $10^{3}$ respectively. An especially illuminating case is afforded by the important problem of complexing the toxic cation $\mathrm{Cd}^{2+}$ while leaving $\mathrm{Ca}^{2+}$ and $\mathrm{zn}^{2+}$ untouched. Cryptand 15 displays exceptionnally high selectivity for $\mathrm{Cd}^{2+}$ with respect to $\mathrm{Zn}^{2+}$ and $\mathrm{Ca}^{2+}$ (factors of $6.10^{5}$ and $2.10^{7}$ ). It may be ascribed to the operation of a double parameter discrimination: because of its nitrogen sites ligand $\underline{\underline{15}}$ strongly favours $\mathrm{Cd}^{2+}$ and $\mathrm{zn}^{2+}$ over $\mathrm{Ca}^{2+}$ but, because of its large cavity, it is unable to form stable complexes with $\mathrm{zn}^{2+}$. The selectivities are even higher for $\mathrm{Pb}^{2+}$ with respect to $\mathrm{Zn}^{2+}$ and $\mathrm{Ca}^{2+}$. Thus, cryptands like $\underline{\underline{15}}$ or derivatives using similar principles, may represent important assets in the control of toxic heavy metal cations in the environment or in organisms.

Attachment of anionic sites yields macrobicyclic complexones like $\underline{17}$ for instance (Ref.16). Such sites usually increase the stabilities and shift them in favour of small and more highly charged cations, thus diminishing the impact of cavity size.

Transition metal and lanthanide [2]-cryptates have been much less studied at present, although the special coordination geometries imposed by the ligand may lead to many new features like spectral, redox and magnetic properties, stabilization of unusual oxidation states, models for strained coordination shells etc. The cavity size is too large in compounds of the [2.2.2] type for efficient complexation of the small transition metal cations. However, $\left[\mathrm{Co}^{2+} \subset 2.2 .1\right]$ forms easily (Ref.6) and displays an uncommon pentagonal bipyramidal coordination (Ref.17). The smaller tetraaza ligand 18 forms stable $\mathrm{Cu}^{2+}, \mathrm{Ni}^{2+}$, $\mathrm{Co}^{2+}$ complexes for which a octahedral structure like 18 bis may be considered.

$\underline{\underline{18}}$

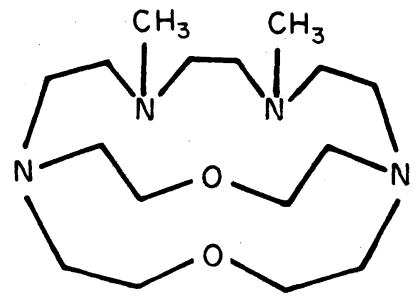

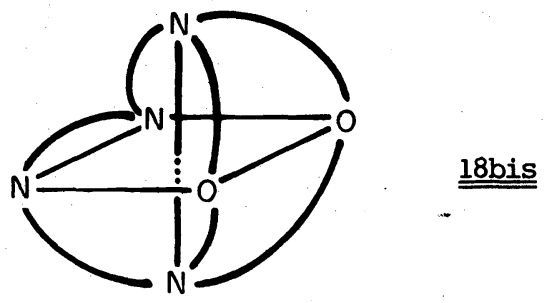

Very little is known about lanthanide cryptates but $\mathrm{La}^{3+}$ and $\mathrm{Pr}^{3+}$ complexes of [2.2.1] have been observed (Ref.18). More detailed studies would be justified.

\section{Cation exchange kinetics.}

In addition to its thermodynamics, an important characteristic of the cryptate formation process (Fig. 1) is the rate of cation exchange in and out of the cavity. A number of such studies have been performed using various techniques, especially ${ }^{1} \mathrm{H}$ (Ref. 19), ${ }^{13} \mathrm{C}$ (Ref.20) and alkali metal (Ref. 21) NMR spectroscopy. They showed that the dissociation rates are several orders of magnitude slower than those of macrocyclic or antibiotic complexes, and increase as the stability decreases. The formation rates are much slower than the rates of water exchange in the hydration shell of the cations. The transition state for cryptate formation appears to be on the reagent side, i.e. it involves still substantial solvation of the cation. Thus, the most stable cryptates are indeed cation receptors releasing the cation only slowly.

\section{Cryptates as counterions. Alkali anions.}

Let us now switch our point of view from the cryptate as a complex between a cation and a 
ligand, to the cryptate as a single entity, a counterion. To the environment, the anions and the solvent, it appears as a spheroidal cationic species of very large size (about $10 \AA$ in diameter).

Whereas the ionic diameter changes by about $1.7 \AA$ from $\mathrm{Li}^{+}\left(1.56 \AA\right.$ ) to $\mathrm{Cs}^{+}(3.3 \AA)$, complexation of an alkali cation produces a new cation of much larger size (a $6-7 \AA$ increase with respect to $\mathrm{Cs}^{+}$), of lower surface charge density and, as a consequence, interacting with anions and solvent molecules much more weakly than the largest alkali cation $\mathrm{Cs}^{+}$. [ $\mathrm{K}^{+} \subset$ 2.2.2] could thus formally be considered as a "super-heavy" alkali cation. If the associated anion is an electron the resulting species would be a very large "alkali" metal of very low ionization potential, < $1 \mathrm{eV}$ from a very rough extrapolation of the ionization potentials of the alkali metals (compare to the $\mathrm{Li}\left(\mathrm{NH}_{3}\right)_{4}$ species, Ref. 22). It should be very strongly reducing and have an almost free electron.

Indeed, cryptand [2.2.2] strongly enhances the solubility of alkali metals in a variety of organic solvents (Ref.23) including benzene and toluene (Ref.24), yielding solutions which first contain the cryptate cation and solvated electrons together with free ligand. On further metal dissolution the electrons disappear and metal anions $M^{-}$are produced (Ref.25). The formation of $\mathrm{M}^{-}$may be looked upon as the product from reduction of a metal atom by the solvated electron of the $\left[\mathrm{M}^{+} \subset 2.2 .2\right] \mathrm{e}^{-}$species.

The most dramatic illustration of the ability of cryptate counterions to stabilize unusual species is certainly the isolation by Dye et al. of the first salt containing an alkali metal anion, [ $\left.\mathrm{Na}^{+} \subset 2.2 .2\right] \mathrm{Na}^{-}$, as crystals of gold colored shiny metallic appearance (Fig. 3). (Ref.26).
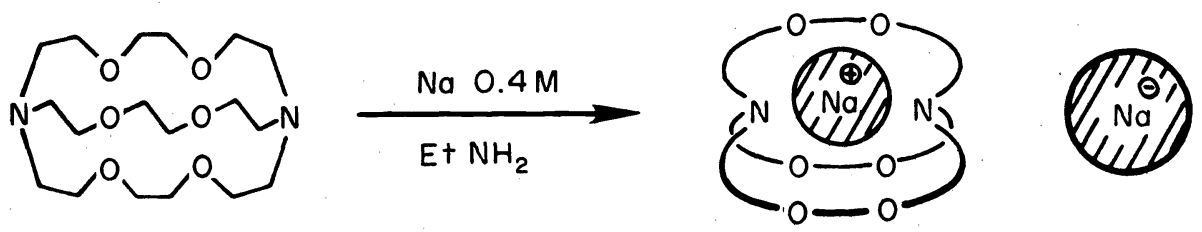

Fig. 3. Formation of the sodium cryptate-sodium anion species.

Its crystal structure has been determined (Ref.27) and its ${ }^{23} \mathrm{Na}$ NMR spectrum contains a narrow, upfield $\mathrm{Na}^{-}$resonance together with the broad $\mathrm{Na}^{+}$resonance of the cryptate (Ref.28). Crystals of $\left[\mathrm{K}^{+} \subset 2.2 .2\right] \mathrm{K}^{-}$have now also been obtained as well as the electride $\left[\mathrm{Na}^{+} \subset 2.2 .2\right] \mathrm{e}^{-}$, a paramagnetic blue solid (Ref.27 \& 29). Other metal anions may be envisaged.

A particularly attractive class of substances is formed by anionic clusters. The first polyatomic anions of the heavy post-transition metals $\left(\mathrm{Sb}_{7}{ }^{3-}, \mathrm{Pb}_{5}{ }^{2-}, \mathrm{Sn}_{9}{ }^{4-}\right.$ ) to be isolated in crystalline salts have cryptate counterions [ $\left.\mathrm{Na}^{+} \mathrm{C} 2.2 .2\right]$ (Ref.30). Complexation of $\mathrm{Na}^{+}$ by [2.2.2] prevents reversion to the starting alloy phase $\mathrm{Na} / \mathrm{metal}$.

These recent results show that [2.2.2] and presumably other cryptands provide access into new chemistry of metals and electrons in solution and in the solid state.

Another aspect of the chemistry of species containing cryptate counterions consists in anion activation by dissolution of salts into organic solvents of low polarity and separation of the cation from the anion through complexation. Thus, highly reactive anions are produced since only little stabilization is available by solvation or interaction with the very large cryptate cation. Such systems have been shown to be of interest in various organic reactions and in anionic polymerization, but these results will not be discussed here. 


\section{CYLINDRICAL MACROTRICYCLIC CRYPTATES}

Cylindrical macrotricyclic ligands of type $C$ present new topological features with respect to the macrobicyclic ligands B. They are formed by two macrocycles linked by two bridges. They define three cavities: two lateral circular cavities inside the macrocycles and a central cavity. Modifying the size of the macrocycles and the length of bridges changes the sizes of the lateral and central cavities. Thus, a multitude of structural modifications may be imagined opening the way to systems designed towards various properties. The first macrotricyclic cryptands to be synthesized, compounds $\underline{\underline{19}}-\underline{\underline{23}}$, contain oxygen binding sites and nitrogen atoms as both binding and structural connecting sites (Ref.31-33). They should thus be suited for $A C$ and $A E C$ complexation.
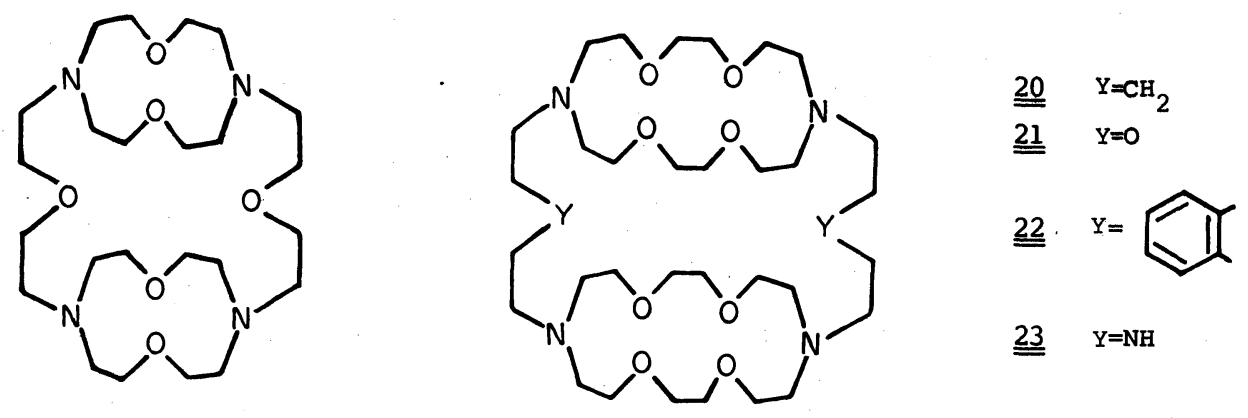

$\underline{\underline{19}}$

Mononuclear and Binuclear Macrotricyclic Cryptates.

Like their macrobicyclic analogs, cryptands 19-23 yield complexes with various metal cations. Their formation is easily observed by NMR spectroscopy and by solubilization of inorganic salts in organic solvents. However two kinds of complexes may be detected, having either $1 / 1$ or $2 / 1$ cation/ligand stoechiometry. In these cylindrical ligands the two macrocycles may each serve as binding site for one cation, so that they form both mononuclear and binuclear [3]-cryptates (Ref.32 \& 33).

The twelve membered macrocycles of ligand $\underline{\underline{19}}$ are too small for cation inclusion into their own cavity. A complexed cation must sit on top of these rings and towards the center of the macrotricyclic cavity. For this reason, a stable binuclear cryptate has been observed only for the most stable complex investigated, that formed with $\mathrm{Ag} \mathrm{NO}_{3}$. The crystal structure of $\left[2 \mathrm{Ag}^{+} \subset \underline{\underline{19}}\right] \mathrm{Ag}\left(\mathrm{NO}_{3}\right)^{2-}$ indeed shows that the two silver cations are located inside the central cavity, each on top of one of the rings and at a distance of $3.88 \AA$. Each $\mathrm{Ag}^{+}$binds to the four sites of one ring and to one of the oxygens in the bridges (Ref.34). In the case of the larger ligands $\underline{\underline{20}}-\underline{\underline{22}}$ binuclear complexes are formed with several AC's and AEC's as well as with $\mathrm{Ag}^{+}$, and $\mathrm{Pb}^{2+}$. The eighteen membered rings are now large enough for cations of size smaller or equal to that of $\mathrm{k}^{+}$or $\mathrm{Rb}^{+}$(about $1.4 \AA$ radius) to penetrate more or less deeply into their cavity. As a consequence, the cations are further apart and the formation of binuclear complexes becomes easier. The crystal structure of [2Na $\left.{ }^{+} \subset \underline{\underline{21}}\right]$ $2 \mathrm{I}^{-}$shows that the two $\mathrm{Na}^{+}$cations are located on each macrocycle and are $6.40 \AA$ apart. This is a much larger distance to than the $\mathrm{Ag}^{+}, \mathrm{Ag}^{+}$distance in $\left[2 \mathrm{Ag}^{+} \subset \underline{19}\right.$, despite the identity of the bridges linking the rings in $\underline{\underline{19}}$ and $\underline{\underline{21}}$; it is due to partial penetration of the $\mathrm{Na}^{+}$cations into the top and bottom macrocyclic cavities (Ref.35). On the basis of these structures and of ${ }^{13} \mathrm{C}-\mathrm{NMR}$ data on the $1 / 1 \mathrm{Ba}\left(\mathrm{NO}_{3}\right){ }_{2} / \underline{\underline{21}}$ complex (Ref. 33), the mononuclear 
complexes of the tricyclic ligands are probably non symmetric with the cation located on a ring on one side of the central cavity. One can then describe the complexation properties of the macrotricyclic cryptands $\underline{\underline{19}}-\underline{\underline{22}}$ as the successive formation of non-symmetric mononuclear and symmetric binuclear [3]-cryptates as represented schematically in figure 4.

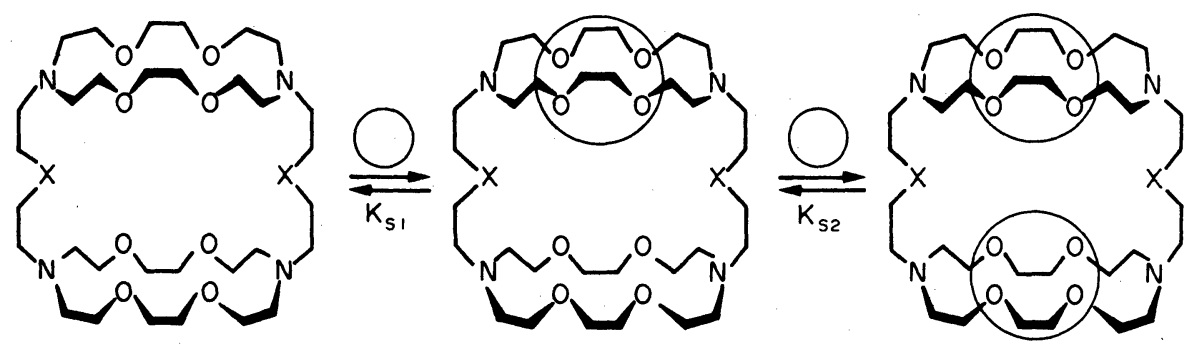

Fig. 4. Equilibria for the successive formation of non-symmetric mononuclear and symmetric binuclear macrotricyclic cryptates.

Heteronuclear bimetallic [3]-cryptates may also be obtained. Thus, in the presence of equal quantities of $\mathrm{AgNO}_{3}$ and $\mathrm{Ba}\left(\mathrm{NO}_{3}\right)_{2}$, ligand $\underline{\underline{21}}$ forms an equilibrium mixture of the two homonuclear complexes, [2 $\left.\mathrm{Ag}^{+} \subset \underline{\underline{21}}\right]$ and $\left[2 \mathrm{~Pb}^{2+} \subset \underline{\underline{21}}\right]$, and of the heteronuclear complex $\left[\mathrm{Ag}^{+} \mathrm{Pb}^{2+} \subset \underline{\underline{21}}\right]$.

\section{Stability constants and kinetic processes}

The stability constants of the $1 / 1$ and $2 / 1$ complexes of the cylindrical macrotricyclic ligands correspond to the equilibria shown in Fig. 4. With ligand 19 , the AC complexes have stabilities comparable to those of macrocyclic ligands except for the larger cations $\mathrm{Rb}^{+}$ and $\mathrm{Cs}^{+}$which probably fit better into the cavity; the AEC's however form remarkably stable complexes $\left(\log K_{s}\right.$ of the order of 7 in water (Ref.36). The larger macrotricycles $\underline{\underline{20}}-\underline{\underline{22}}$ show two main features:

1) the stabilities $K_{s 1}$ and selectivities of the 1/1 AC and AEC complexes of $\underline{\underline{20}} \underline{\underline{22}}$ are similar to those of the macrocycle $\underline{\underline{10}}$;

2) the stabilities and selectivities of the binuclear complexes $\left(K_{s 2}\right.$, see Fig.4) are similar to those of the $1 / 1$ complexes; it is especially remarkable that $K_{s 2}$ for the formation of $\left[2 \mathrm{Ba}^{2+} \mathrm{C} \underline{\underline{21}}\right]$ is as high as $K_{s 1}$ for $\left[\mathrm{Ba}^{2+} \mathrm{C} \underline{\underline{21}}\right]$.

Both results lead to the conclusion that the larger macrotricycles contain two almost independent macrocyclic units.

Kinetic processes have been observed in several cases. Temperature dependent ${ }^{13} \mathrm{C}-\mathrm{NMR}$ measurements have allowed to detect an intra-molecular cation exchange process in the $1 / 1$ $\mathrm{Ca}^{2+}, \mathrm{Sr}^{2+}$ and $\mathrm{Ba}^{2+}$ complexes of ligand 19 . The spectral changes observed agree with an internal cation exchange between "top" and "bottom" of the molecule (Fig.5). Intermolecular exchange occurs also, but at much slower rate than the internal fluxional process (Ref.36). It is probable that the same internal process is present in the AC complexes of $\underline{\underline{19}}$ and in the non-symmetrical $1 / 1$ complexes of $\underline{\underline{20}}-\underline{\underline{22}}$ (Ref.33) but at much faster rates. These interesting dynamic features of macrotricyclic complexes also bear relation to the elementary jump process between binding sites which may occur in cation channels. 

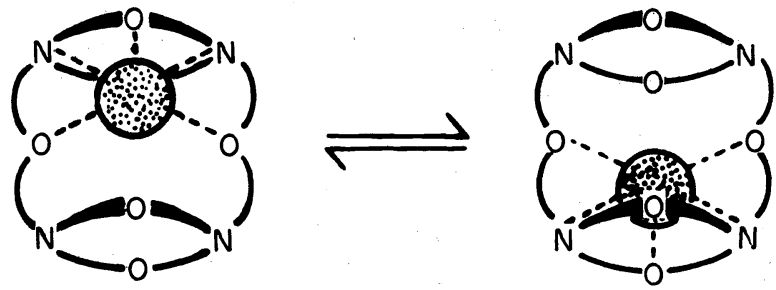

Fig. 5. Intramolecular cation exchange in mononuclear complexes of the macrotricyclic ligand $\underline{\underline{19}}$.

Prospects for the chemistry of cylindrical macrotricyclic ligands lie in the synthesis of ligands which may form binuclear transition metal complexes via the incorporation of suitable macrocyclic units in the macrotricyclic structure. Then, regulation of the size of the central cavity via the length of the bridges may provide either strong cation-cation interactions at short distances, or, at long distances, further inclusion of a substrate of given size, held between the two metal cations and selected by them. The latter cascade process has obvious implications for coordination chemistry and catalysis.

\section{SPHEROÏDAL MACROTRICYCLIC LIGANDS}

Macrotricyclic ligands of type $D$ represent a close approach to a spherical molecule. In terms of spherical recognition, such a system displays a particularly attractive topology (Ref.1) since it contains a spherical cavity into which substrates may be included. Two such molecules $\underline{\underline{24}}, \underline{\underline{25}}$ have been synthesized via a route involving three high dilution reactions for the successive construction of a macrocyclic, a macrobicyclic and the final macrotricyclic architecture. The macrobicyclic analog $\underline{\underline{26}}$ has been prepared for comparison purposes (Ref.37 \& 38).

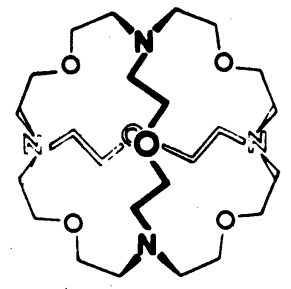

$\underline{\underline{24}}$

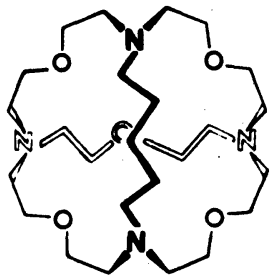

$\underline{\underline{25}}$

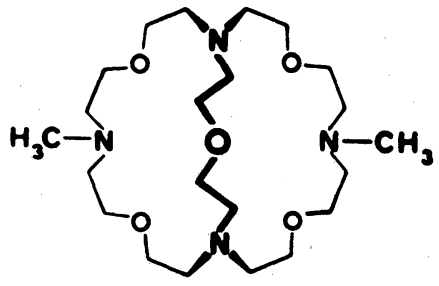

$\underline{\underline{26}}$

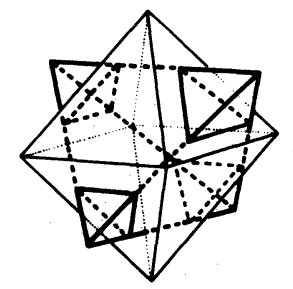

27

Ligand $\underline{\underline{24}}$ in its $i_{4}$ form (Ref.37) contains a spherical cavity (of about $1.7 \AA$ radius), lined with ten binding sites in an octahedrotetrahedral arrangement: the four nitrogens are located at the corners of a tetrahedron and the six oxygens are at the corners of an octahedron; the centers of the two polyhedra coincide and the ten corners lie on the same sphere (see 27). 


\section{Spherical Cation Cryptates.}

Ligands like $\underline{\underline{24}}$ and $\underline{\underline{25}}$ have the ideal topology for complexing the spherical AC and AEC's. Complexation of $\mathrm{K}^{+}, \mathrm{Rb}^{+}, \mathrm{Cs}^{+}, \mathrm{Ba}^{2+}$ has been observed. These complexes are spherical [3]-cryptates, e.g. [ $\left.\mathrm{Cs}^{+} \subset \underline{\underline{24}}\right]$, where the cations are included in the central cavity of the ligand in the $i_{4}$ form. The stability constants are high $\left(\log K_{s}=3.4,4.2\right.$ and 3.4 for $\mathrm{K}^{+}$, $\mathrm{Rb}^{+}, \mathrm{Cs}^{+}$respectively in water) and the $\mathrm{Cs}^{+}$complex appears to be the most stable known to date. The cation exchange rates are slow, with high activation energies for dissociation of the complex (of the order of $16 \mathrm{kcal} / \mathrm{mole}$ ) (Ref.37). It is interesting to note that the macrobicyclic ligand $\underline{\underline{5}},[3.2 .2]$, which has about the same cavity diameter (Ref.1) as $\underline{\underline{24}}$ and almost the same number of binding sites, forms complexes which are less stable by a factor of 10-100 and have much faster cation exchange kinetics (Ref.20).

\section{Molecule cryptates.}

Ligand $\underline{\underline{24}}$ forms an inclusion complex with the ammonium cation [ $\mathrm{NH}_{4}{ }^{+} \mathrm{C} \underline{\underline{24}}$ ] which undergoes slow exchange. It represents topologically the optimal $\mathrm{NH}_{4}^{+}$receptor (Fig.6); the cation forms a tetrahedral array of hydrogen bonds towards the four nitrogen sites and there are six electrostatic $\mathrm{O} \rightarrow \mathrm{N}^{+}$interactions, one along the bisectrix of each of the $\mathrm{H}-\mathrm{N}-\mathrm{H}$ angles, in agreement with the crystal structure (Ref.39).
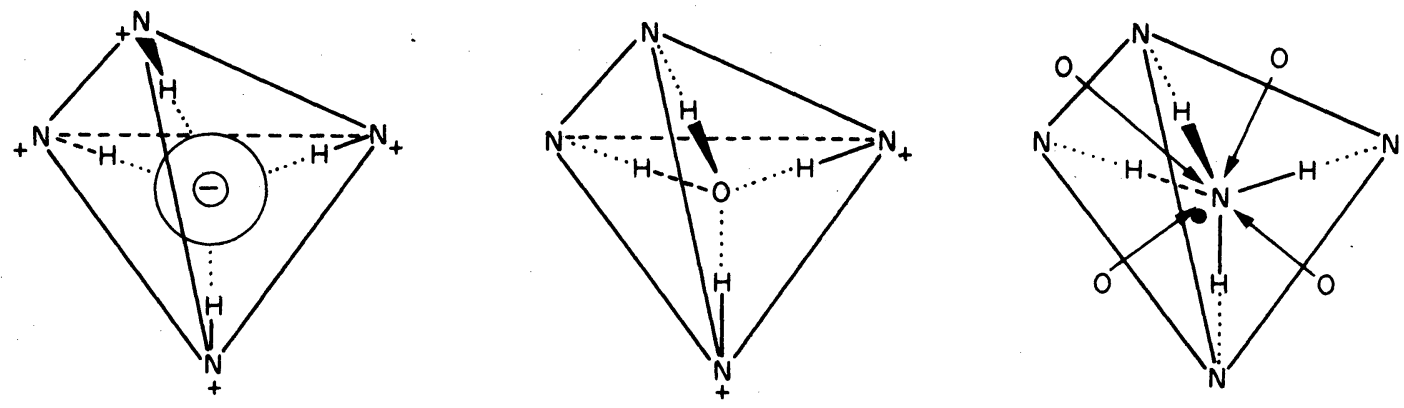

Fig. 6. Tetrahedral binding of $\mathrm{NH}_{4}^{+}$(left), $\mathrm{H}_{2} \mathrm{O}$ (center) and $\mathrm{Cl}^{-}$(right) by the spheroidal macrotricyclic ligand $\underline{\underline{24}}$ (left), its diprotonated form (center) and its tetraprotonated form (right). For the $\mathrm{NH}_{4}^{+}$complex (left) only four of the six possible electrostatic $0 \rightarrow \mathrm{N}^{+}$interactions are shown.

Ligands $\underline{\underline{24}}$ and $\underline{\underline{25}}$ have abnormal acid-base properties; the second protonation is as easy or easier than the first one, $\mathrm{p} K_{2} \geqslant \mathrm{p} K_{1}$ ! and the third protonation is much more difficult. The bicyclic compound $\underline{\underline{26}}$ however behaves as a regular tetramine. The present results agree with the formulation of the diprotonated ligand in fact as an inclusion complex of a water molecule into the cavity of the diprotonated ligand, $\left[\mathrm{H}_{2} \mathrm{O} \subset \underline{\underline{24}}-\mathrm{H}_{2}{ }^{2+}\right]$ (Fig. 6). The diprotonated species is thus a water receptor molecule. The water molecule is held in an ideal hydrogen bonding array with an ice-like, tetrahedral arrangement; it accepts two H-bonds from the $\mathrm{NH}^{+}$sites and donates two H-bonds to the unprotonated amino sites, the whole system probably undergoing fast proton transfer. It represents a particularly attractive case for the study of three dimensional proton tunneling in an isolated system,like the proton cryptate $\left[1.1 .1, \mathrm{H}^{+}\right]$is an isolated system undergoing linear proton tunneling (Ref.5b). Furthermore, the abnormal protonation features now become a cooperativity effect mediated by an allosteric effector molecule, $\mathrm{H}_{2} \mathrm{O}$. Finally, NMR data show that proton exchange between $\left[\mathrm{H}_{2} \mathrm{O} \subset \underline{\underline{24}}-\mathrm{H}_{2}{ }^{2+}\right.$ ] and the free ligand is very slow $\left(<20 \mathrm{sec}^{-1}\right.$ at $\left.25^{\circ} \mathrm{C}\right)$, which implies also that water exchange is slow, pointing to a particularly stable water complex. 
The spherical macrotricyclic cryptands are thus molecule receptors displaying tetrahedral recognition of small inorganic molecules. Further developments along this line may be envisaged (for instance $\mathrm{NH}_{3}+\underline{\underline{24}} ; \mathrm{H}_{2} \mathrm{~S}+\left(\underline{\underline{24}}-\mathrm{H}_{2}^{2+}\right.$ ); perhaps even $\mathrm{CH}_{4}+\underline{\underline{24}}$ or $\left.\mathrm{Ar}+\left(\underline{\underline{24}}-\mathrm{H}_{4}^{4+}\right) !\right)$.

\section{Anion Cryptates.}

NMR studies as well as measurements with halide ion selective electrodes have shown that anion complexes may be obtained with the tetraprotonated forms of ligands 24-26, like in the case of diprotonated macrobicyclic diamines forming halide inclusion complexes, the katapinates (Ref.40). With the present ligands the halide inclusion complexes are macrotricyclic anion cryptates, $\left[\mathrm{x}^{-} \subset \mathrm{LH}_{4}^{4+}\right]$ (Fig. 6), where the spherical halide ion $\mathrm{x}^{-}$is held by a tetrahedral array of $\stackrel{+}{\mathrm{N}}-\mathrm{H} . . . \mathrm{x}^{-}$hydrogen bonds inside the molecular cavity of the tetraprotonated $i_{4}$ form of the ligands $L$, in agreement with the crystal structure of

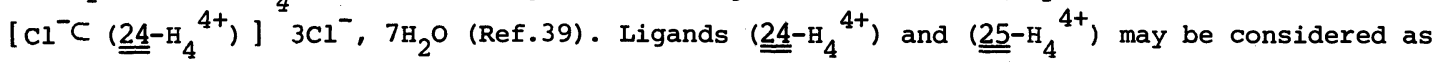
the topologically optimal receptors for spherical anions. The chloride complexes are very stable $\left(\log K_{s}>\sim 4.0\right.$ in water) and the $\mathrm{Cl}^{-} / \mathrm{Br}^{-}$selectivity is high with both ligands. Comparing the $\mathrm{Cl}^{-}$and $\mathrm{Br}^{-}$complexes of $\underline{\underline{24}}$ and $\underline{\underline{25}}$ with those of the macrobicyclic analog $\underline{\underline{26}}$, gives evidence for the operation of a marked macrotricyclic effect: the unique high stability and high selectivity of the $\mathrm{Cl}^{-}$complexes of the spherical macrotricyclic ligands are not shown by the macrobicyclic system 26; they may be attributed to the presence of a closed, rigid cavity, into which $\mathrm{Cl}^{-}$fits best and which resists deformation. $\mathrm{F}^{-}$complexes are formed, but their stabilities are not yet known; $\mathrm{I}^{-}$does not form a stable complex, nor do other anions like $\mathrm{NO}_{3}^{-}, \mathrm{SO}_{4}{ }^{2-}$ etc.

It seems clear that the design of cavities acting as receptors for other anions is feasible; the major requirement is to provide the correct array of hydrogen bonds for the anion while hindering as much as possible the hydration of the hydrogen bond donor sites.

\section{PROSPECTS}

Various lines for future development of the chemistry of macropolycyclic systems may be recognized. Apart from the organic or bioorganic chemistry of macropolycyclic molecules, three broad fields of investigation may be selected as examples within the domain closer to inorganic chemistry:

1) the development of receptors with recognition sites other than spherical or tetrahedral, for instance bipyramidal or octahedral;

2) the synthesis of ligands bearing several cation complexing sites and thus forming binuclear or polynuclear complexes in which distance and arrangement of the cations may be regulated via ligand structure;

3) cascade complexes formed by substrate inclusion between metal cations of bi- or polynuclear complexes, subsequent to the inclusion of these cations themselves into the ligand; such complexes allow the study of cascade recognition and may have important developments in bioinorganic modelling and in catalysis. The sequential complexation process involved in the formation of cascade complexes is depicted in figure 7 for the case of a cylindrical macrotricyclic ligand; as already noted above, this system is particularly attractive for its versatility, but other ligand topologies may be envisaged. 


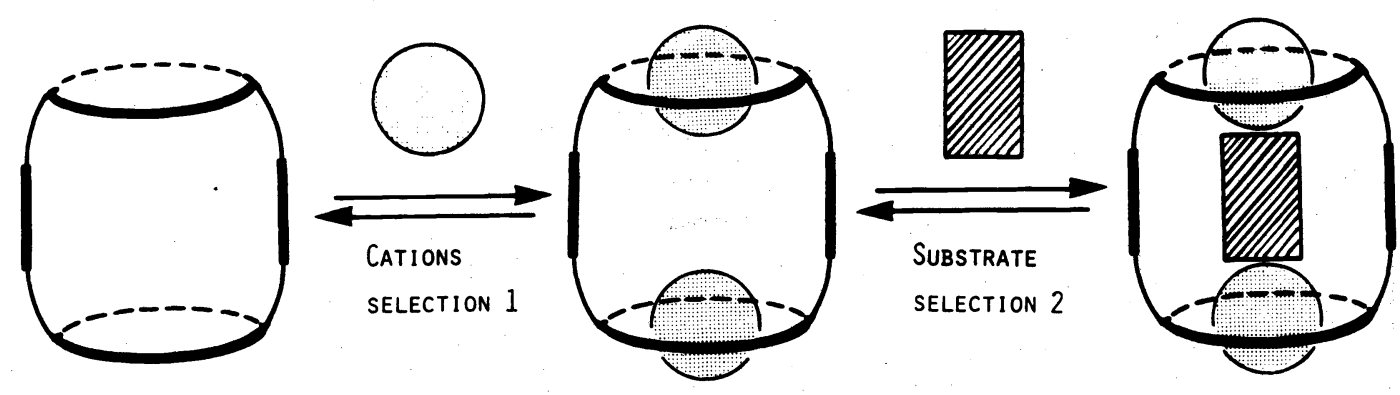

Figure 7

It does not seem too daring a prediction, that the symbiosis of the architectural power of organic synthesis with the multiform properties of inorganic ions and molecules, provided by the macropolycyclic ligands, should assure a bright future to this field of chemistry.

Acknowledgement - I wish to express my gratitude to the coworkers whose skill and dedication allowed to realize the work described above. Their names appear in the references listed. The expenses incurred were borne by grants from the Centre National de la Recherche Scientifique and the Délégation Générale à la Recherche Scientifique et Technique.

\section{REFERENCES}

1. J.M. Lehn, Structure and Bonding 16, 1-69 (1973)

2. C.J. Pedersen and H.K. Frensdorff, Angew. Chem. 84, 16-26 (1972); Angew. Chem. Internat. Edit. $11,16-25$ (1972).

3. Structure and Bonding, Springer Verlag, Berlin, vol 16 (1973).

4. L.F. Lindoy, Chem. Soc. Rev. 4 , 421-441 (1975).

5. a) B. Dietrich, J.P. Sauvage and J. Blanzat, Tetrahedron 29, 1629-1645 (1973); b) J. Cheney and J.M. Lehn, J.C.S. Chem. Comm. 487-488 (1972).

6. B. Dietrich, J.M. Lehn and J.P. Sauvage, Tetrahedron 29, 1647-1658 (1973).

7. B. Metz, D. Moras and R. Weiss, Chem. Comm. 444-445 (1971).

8. J.M. Lehn and J.P. Sauvage, J. Am. Chem. Soc. 97, 6700-6707 (1975).

9. Yu. A. Ovchinnikov, V.T. Ivanov and A.M. Shkrob, Membrane Active Complexones, Elsevier, Amsterdam (1974).

10. W.H. Müller, Naturwiss. 57, 248 (1970); W.H. Müller and W.A. Müller, Naturwiss. 61,455 (1974).

11. B. Dietrich, J.M. Lehn and J.P. Sauvage, J.C.S. Chem. Comm. 15-16 (1973).

12. Y.M. Cahen, J.L. Dye and A.I. Popov, J. Phys. Chem. 79, 1289-1291 (1975).

13. G. Anderegg, Helv. Chim. Acta 58, 1218-1225 (1975); E. Kauffmann, J.M. Lehn and J.P. Sauvage, Helv. Chim. Acta 59, 1099-1111 (1976).

14. B. Dietrich, J.M. Lehn and J.P. Sauvage, Chem. Comm. 1055-1056 (1970); B. Dietrich and J.M. Lehn, unpublished results.

15. J.M. Lehn and F. Montavon, Helv. Chim. Acta 59, 1566-1583 (1976) and unpublished results.

16. J.M. Lehn and P. Vitali, unpublished results. P. Vitali, Thèse de $3^{\circ} \mathrm{Cycle}$, Université Louis Pasteur Strasbourg (1975). 
17. F. Mathieu and R. Weiss, J.C.S. Chem. Comm. 816 (1973).

18. J.M. Lehn and J.P. Sauvage, unpublished results.

19. J.M. Lehn, J.P. Sauvage and B. Dietrich, J. Am. Chem. Soc. 92, 2916-2918 (1970).

20. E. Kauffmann and J.M. Lehn, unpublished results.

21. J.M. Ceraso and J.L. Dye, J. Am. Chem. Soc. 95, 4432-4434 (1973); J.P. Kintzinger and J.M. Lehn, ibid. 96, 3313-3314 (1974); Y.M. Cahen, J.L. Dye and A.I. Popov, J. Phys. Chem. 79, 1292-1295 (1975); see also stopped-flow studies in V.M. Loyola, R.G. Wilkins and R. Pizer, J. Am. Chem. Soc. 97, 7382-7383 (1975).

22. N. Mammano and M.J. Sienko, J. Am. Chem. Soc. 90, 6322-6324 (1968).

23. M.T. Lok, F.J. Tehan and J.L. Dye, J. Phys. Chem. 76, 2975-2981 (1972).

24. B. Kaempf, S. Raynal, A. Collet, F. Schué, S. Boileau and J.M. Lehn, Angew. Chem. 86, 670-671 (1974); Angew. Chem. Internat. Ed. 13, 611-612 (1974).

25. J. Lacoste, F. Schué, S. Bywater and B. Kaempf, Polymer Letters 14, 201-206 (1976).

26. J.L. Dye, J.M. Ceraso, M.T. Lok, B.L. Barnett and F.J. Tehan, J. Am. Chem. Soc. 96, 608609 (1974); J.L. Dye, C.W. Andrews and S.E. Mathews, J. Phys. Chem. 79, 3065-3070 (1975).

27. F.J. Tehan, B.L. Barnett and J.L. Dye, J. Am. Chem. Soc. 96, 7203-7208 (1974).

28. J.L. Dye, C.W. Andrews and J.M. Ceraso, J. Phys. Chem. 79, 3076-3079 (1975).

29. J.L. Dye, M. DaGue and J.M. Lehn, unpublished observations.

30. J.D. Corbett, D.G. Adolphson, D.J. Merryman, P.A. Edwards and F.J. Armatis, J. Am. Chem. Soc. 97, 6267-6268 (1975); J.D. Corbett and P.A. Edwards, J.C.S. Chem. Comm. 984-985 $(1975)$.

31. J. Cheney, J.M. Lehn, J.P. Sauvage and M.E. Stubbs, J.C.S. Chem. Comm. 1100-1101 (1972).

32. J.M. Lehn, J. Simon and J. Wagner, Angew. Chem. 85, 621,622-623 (1973); Angew. Chem. Internat. Ed. 12, 578-579, 579-580 (1973).

33. J.M. Lehn and J. Simon, to be published; J. Simon, Thèse de Doctorat d'Etat, Université Louis Pasteur Strasbourg, 1976.

34. R. Wiest and R. Weiss, J.C.S. Chem. Comm. 678-679 (1973).

35. M. Mellinger, J. Fischer and R. Weiss, Angew. Chem. 85, 828-829 (1973); Angew. Chem. Internat. Edit. 12, (1973).

36. J.M. Lehn and M.E. Stubbs, J. Am. Chem. Soc. 96, 4011-4012 (1974).

37. E. Graf and J.M. Lehn, J. Am. Chem. Soc. 97, 5022-5024 (1975).

38. E. Graf and J.M. Lehn, unpublished results.

39. B. Metz, J.M. Rozalky and R. Weiss, J.C.S. Chem. Comm. 533-534 (1976).

40. C.H. Park and H.E. Simmons, J. Am. Chem. Soc. 90, 2431-2432 (1968). 